\title{
Emergency Department Management of Penetrating Neck Trauma
}

\author{
Erin Payne* \\ Emergency Medicine Resident Physician, USA \\ Received: 漹 July 03, 2018; Published: 鲇July 10, 2018 \\ *Corresponding author: Erin Payne, PGY-2, Emergency Medicine Resident Physician, USA
}

\section{Introduction}

Penetrating neck trauma is not only relatively common, but associated with approximately 50\% incidence of serious vascular, aerodigestive, or neurologic injuries, as well as significant risk of morbidity and mortality[1]. These injuries present several concomitant challenges for emergency physicians, as they require elements of airway management, hemorrhage control, hemodynamic resuscitation, performance of the trauma survey and other components of advanced trauma life support, knowledge about potential injuries and other complications of penetrating neck trauma, and the ability to perform rapid evaluation and initial management of penetrating neck trauma[2,3].

Stable patients who do not require immediate intervention for vascular or airway compromise should undergo early assessment of the wound. Local anesthetic may be required in order to facilitate an exam which is thorough enough to determine whether or not the platysma has been breached. By definition, penetrating neck injuries must violate the platysma; those which do not are superficial neck injuries[4]. Several important structures may be injured as a result of penetrating neck trauma[1,4]. One quarter of these patients will have arterial injury, with $80 \%$ of those involving the carotid arteries5. One quarter will have aerodigestive injuries2, which are plagued by a lack of initial physical findings and markedly increased morbidity and mortality associated with delayed diagnosis[1].

\section{Trauma Association Guidelines and Recommendations}

According to the 2013 guidelines of the Western Trauma Association (WTA) regarding the management of penetrating neck trauma, management of these injuries should include: following Advanced Trauma Life Support protocols for identification of life-threatening injuries and initiation of immediate life-saving interventions; temporizing hemorrhage control of active bleeding via manual pressure or balloon catheter tamponade; establishment of secure airway, including surgical airway if necessary due to failure of orotracheal techniques; and emergent surgical intervention for patients exhibiting hemodynamic instability or hard signs[2]. Hard signs include airway compromise (indicated by hoarseness, stridor), massive subcutaneous emphysema or gurgling wound with air bubbling through it, shock, active bleeding, expanding or pulsatile hematoma, other signs of vascular injury such as bruit or pulse deficit, dysphagia, hematemesis, and neurologic deficit[1,2]. Any symptomatic zone II injuries, which WAT defines as those above the line of the clavicles, should also proceed to the operating room (OR), for further evaluation in a controlled setting where escalation of care is readily available[2].

For stable patients with a penetrating wound and suspicion of resultant injuries but no hemodynamic instability or hard signs, non-operative evaluation via advanced imaging is appropriate for most zone I and III injuries, as well as asymptomatic zone II injuries[5]. As compared to mandatory surgical exploration, selective operative management of zone II penetrating neck trauma has shown equivalent patient safety diagnostic accuracy, with reduced incidence and associated costs of unnecessary operations[1,2,6]. Eastern Association for the Surgery of Trauma (EAST) recommendations agree with these findings and recommend selective surgical management as well[1]. For these patients, computed tomography angiography (CTA) is recommended, as it is highly sensitive for identifying significant injuries which need further operative management, while decreasing the incidence of unnecessary operations[1,3,7,8]. Esophageal injuries are best evaluated by contrast esophagography or esophagoscopy, if suspicion warrants further evaluation after negative CTA[1,3]. Venous injuries are not uncommon, but rarely require surgical intervention[1,2,4].

For stable patients without suspicion of serious injuries, observation and serial examination versus radiographic evaluation is appropriate[2,6]. If the former option is chosen, it should be done cautiously, keeping in mind that while physical examination is quite reliable for excluding arterial injuries, it is less dependable for excluding aerodigestive injuries[7]. For transcervical gunshot wounds, the observation strategy is controversial, as these wounds have a higher incidence of significant injuries and are more likely to involve multiple zones[1,2]. For this reason, EAST recommends that physicians have a low threshold for utilizing advanced imaging[1]. Patients who are candidates for observation should undergo serial examinations every 6 to 8 hours for a total of 24 to 36 hours[3]. 


\section{To Zone or Not to Zone}

Anatomic zones are much more relevant to the surgical approach than they are to the initial evaluation and management[2]. While the line between zone I and zone II has been changed from the clavicles to the cricoid cartilage, this has been without great significant clinical relevance[9], and many still prefer the former definition, which was based on surgical approach and exposure rather than on presumed underlying injuries[2,3]. WTA guidelines have opted to utilize the initial boundaries, where zone I lies below the level of the clavicles[2].

For initial evaluation and management of penetrating neck trauma outside of the $\mathrm{OR}$, recent evidence suggests that anatomic zones should no longer be a major consideration. The apparent anatomic zone of external wounds does not appear to reliably correlate with underlying internal injuries[10], and the use of anatomic zones in management algorithms does not appear to improve patient outcomes[11]. As a suggested alternative, all patients with hemodynamic instability and/or hard signs should go to the OR emergently regardless of zone, and all stable patients with concern for serious underlying injury should be evaluated with CTA $[4,12]$, which is now readily available and reliable at detecting and excluding injuries regardless of zone[1,12].The exception to the zoneless approach would be for injuries beneath the clavicles, for which management should be based on the potential for thoracic and axillary injuries[3,4].

\section{Airway}

Airway management can be more difficult in penetrating neck trauma than in many other situations, due to the possibility of disruption of normal anatomic airway structures, or occlusion by hemorrhage or hematoma[3,4]. Such cases require the physician to be prepared ahead of time to work through a difficult airway algorithm[4,13]. Many of the hard signs of penetrating neck injury are important indications of potential airway injury-including hoarseness, stridor, dyspnea, subcutaneous emphysema, or air bubbling through the wound[3,4,13]. In the absence of obvious structural deformity of the airway anatomy, rapid sequence orotracheal intubation should be attempted and has a satisfactory success rate[13,14]. In the presence of anatomic deformities, alternative techniques are preferred. For compression by a large hematoma, for example, fiberoptic intubation should be attempted if available[3,13], both because it allows the physician better visualization to avoid intubating a false tracheal lumen created by the injury plane, and because it allows the patient to remain spontaneously breathing as long as possible[4].

When there is massive airway or midface deformity, inability to visualize or identify the airway during direct or fiberoptic laryngoscopy attempts, or any otherwise failed intubation with inability to obtain adequate oxygenation or ventilation; surgical airway is immediately indicated. Cricothyrotomy is preferred for its safety and the quickness with which it can usually be performed; unless there are contraindications such as transection of the trachea below the level of the cricothyroid membrane[3,4,15], in which case exposure and intubation through the tracheal defect3,13 or tracheostomy will be necessary[3,4,15]. Airway injuries inferior to this point may be very difficult to identify and manage and confer higher mortality. When tracheal intubation is unable to ventilate these patients due to lower airway injuries, extra corporeal membrane oxygenation may be considered[13].

\section{Hemorrhage}

Hemorrhage is a significant cause of mortality in patients with penetrating neck injuries; therefore, hemorrhage control is a crucial aspect of management. Hemorrhage control may be attempted with direct external compression[3,4,16], but if this is not successful, internal digital compression, gauze packing[3], or a foley catheter balloon may be used to tamponade the bleeding from within. When the balloon catheter is used, the wound may be closed tightly around the balloon catheter insertion site to facilitate tamponade. The balloon should be left in place until surgical repair is performed, or if angiography is performed and excludes arterial injury, for approximately 72 hours to allow hemostasis[3,4,6,16-18].

\section{Cervical Spine}

While penetrating neck injuries of other mechanisms have not been associated with clinically significant cervical spine injuries in the literature[19,20], a low proportion $(0.4-1.4 \%)$ of gunshot wounds to the neck do result in unstable cervical spine fractures or cervical spinal cord injuries[20,21]. These injuries are almost always associated with neurologic deficit on initial assessment, and their incidence is much lower than that of other injuries such as vascular injuries[19,20]. In such cases, cervical spine immobilization (CSI) should be considered if there significant and specific concern for such an injury[4,21].In most other cases, cervical spine immobilization (CSI) should not be routinely performed for penetrating neck trauma, because it is low yield and takes time and focus off of the assessment and management of other injuries[4,19]. CSI makes pre-hospital transport significantly more time-consuming[19] and will inevitably impair physicians' ability to safely and efficiently assess and manage the airway and vascular injuries[4,19].

\section{Conclusion}

Penetrating neck trauma presents a complex set of challenges for emergency physicians[1,2,4,5], who are in a position to reduce morbidity and mortality by preparing to evaluate and manage these injuries in a timely and evidence-based manner[2,3,16]. In summary, unstable patients or those with hard signs should be taken to the OR emergently after a definitive airway is secured and hemorrhage is controlled[2-4]. Those who are stable without hard signs should be evaluated with CTA[1,3,7,8], and additionally, contrast esophogram or esophagoscopy if there is lingering concern for esophageal injury[1,3]. Observation management should be selected with caution, as aerodigestive injuries lack early signs and are associated with much higher morbidity and mortality if diagnosed late[1,2,7]. Airway management is more difficult in these patients, due to airway injuries and compression or obstruction by blood or adjacent injuries[3,4,13]. Physicians should be prepared to work through difficult airway algorithm[3,4,13-15], including techniques such as performing a cricothyrotomy[3,4,15], or intubating through an exposed tracheal injury $[3,13]$. Hemorrhage 
control is also extremely important and can usually be accomplished with techniques such as direct external compression, digital internal compression, gauze packing, or foley catheter balloon tamponade $[3,4,16]$. Cervical spine immobilization should not be routinely used, as it delays evaluation and management of more likely life-threatening injuries[4,19]; with the exception of gunshot wounds or patients with neurologic deficits, in which case it should be considered[20,21].

\section{References}

1. Tisherman SA, Bokhari F, Collier B (2008) Clinical practice guideline: penetrating zone II neck trauma. J Trauma 64(5): 1392-1405.

2. Sperry JL, Moore EE, Coimbra R (2013) Western Trauma Association critical decisions in trauma: penetrating neck trauma. J Trauma Acute Care Surg 75(6): 936-940.

3. Feliciano DV (2015) Penetrating cervical trauma. "Current concepts in penetrating trauma," IATSIC Symposium International Surgical Society, Helsinki, Finland, Augusta 25-29, 2013. World J Surg 39(6): 1363-1372.

4. Nowicki JL, Stew B, Ooi E (2018) Penetrating neck injuries: a guide to evaluation and management. Ann R Coll Surg Engl 100(1): 6-11.

5. Saito N, Hito R, Burke PA, Sakai O (2014) Imaging of penetrating injuries of the head and neck: current practice at a level I trauma center in the United States. Keio J Med 63(2): 23-33.

6. Van Waes OJ, Cheriex KC, Navsaria PH (2012) Management of penetrating neck injuries. Br J Surg 99: 149-154.

7. Inaba K, Branco BC, Menaker J (2012) Evaluation of multidetector computed tomography for penetrating neck injury: A prospective multicenter study. J Trauma Acute Care Surg 72(3): 576-583.

8. Woo K, Magner DP, Wilson MT, Margulies DR (2005) CT angiography in penetrating neck trauma reduces the need for operative neck exploration. Am Surg 71(9): 754-758.

9. Mattox KL, Moore EE, Feliciano DV (2013) Trauma ( $7^{\text {th }}$ edn.); New York: McGraw Hill, USA.

\section{ISSN: 2574-1241}

DOI: 10.26717/BJSTR.2018.06.001387

Erin Payne. Biomed J Sci \& Tech Res

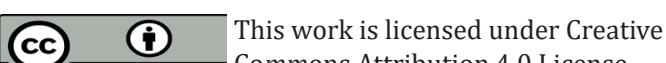

Submission Link: https://biomedres.us/submit-manuscript.php
10. Low GM, Inaba K, Chouliaras K, Branco B, Lam L, et al. (2014) The use of the anatomic 'zones' of the neck in the assessment of penetrating neck injury. Am Surg 80(10): 970-974.

11. Prichayudh S, Choadrachata-anun J, Sriussadaporn S (2015) Selective management of penetrating neck injuries using "no zone" approach. Injury 46(9): 1720-1725.

12. Shiroff AM, Gale SC, Martin ND (2013) Penetrating neck trauma: a review of management strategies and discussion of the 'No Zone' approach. Am Surg 79(1): 23-29.

13. Kummer C1, Netto FS, Rizoli S (2007) A review of traumatic airway injuries: potential implications for airway assessment and management. Injury 38(1): 27-33

14. Mandavia DP, Qualls S, Rokos I (2000) Emergency airway management in penetrating neck injury. Ann Emerg Med 35(3): 221-225.

15. Lee WT, Eliashar R, Eliachar I (2006) Acute external laryngotracheal trauma: diagnosis and management. Ear Nose Throat J 85(3): 179-184.

16. Burgess CA, Dale OT, Almeyda R (2012) An evidence-based review of the assessment and management of penetrating neck trauma. Clin Otolaryngol 37(1): 44-52.

17. Ball CG, Wyrzykowski AD, Nicholas JM (2011) A decade's experience with balloon catheter tamponade for the emergency control of hemorrhage. J Trauma 70(2): 330-333.

18. Navsaria P, Thoma M, Nicol A (2006) Foley catheter balloon tamponade for life-threatening hemorrhage in penetrating neck trauma. World J Surg 30(7): 1265-1268.

19. Stuke LE, Pons PT, Guy JS, Chapleau WP, Butler FK, et al. (2011) Prehospital spine immobilization for penetrating trauma--review and recommendations from the Prehospital Trauma Life Support Executive Committee. J Trauma 71(3): 763-769.

20. Lustenberger T, Talving P, Lam L (2011) Unstable cervical spine fracture after penetrating neck injury: a rare entity in an analysis of 1,069 patients. J Trauma 70(4): 870-872.

21. Rhee P, Kuncir EJ, Johnson L (2006) Cervical spine injury is highly dependent on the mechanism of injury following blunt and penetrating assault. J Trauma 61(5): 1166-1170.

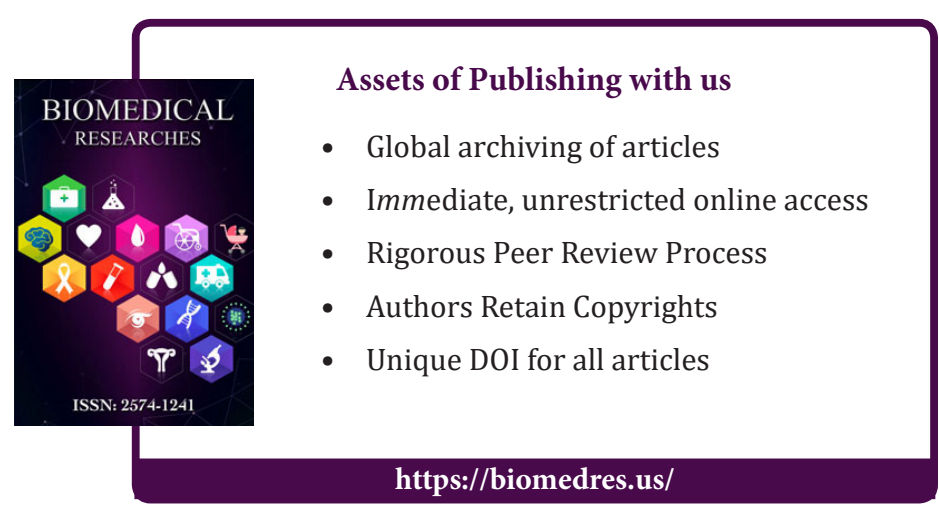

